\title{
Blood Coagulation Factor Fibrinogen in Tumor Pathogenesis of Central Nervous System B-Cell Lymphoma
}

\author{
Justin P. Chan, ${ }^{*}$ Mario Merlini, ${ }^{*}$ Hua-Xin Gao, ${ }^{\dagger}$ Andrew S. Mendiola, ${ }^{*}$ Katerina Akassoglou, ${ }^{* \dagger}$ James L. Rubenstein, ${ }^{\dagger}$ and \\ Jae Kyu Ryu*
}

From the Gladstone Institutes, ${ }^{*}$ the Division of Hematology and Oncology ${ }^{\dagger}$ University of California, San Francisco, San Francisco; and the Department of Neurology, ${ }^{\ddagger}$ Weill Institute for Neurosciences, University of California, San Francisco, San Francisco, California

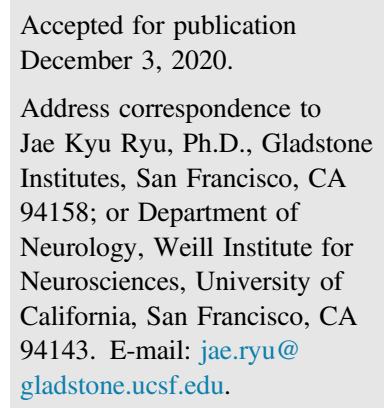

\begin{abstract}
Central nervous system (CNS) lymphoma is an extranodal non-Hodgkin B-cell lymphoma characterized by malignant lymph tissue arising in the brain or spinal cord, associated with inflammation and bloodbrain barrier (BBB) disruption. Although BBB disruption is known to occur in patients with CNS lymphoma, a direct link between these two has not been shown. Herein, abundant deposition of the blood coagulation protein fibrinogen around B-cell lymphoma was detected in CNS lymphoma patients and in the CNS parenchyma in an orthotopic mouse model. Functional enrichment analysis of unbiased cerebrospinal fluid proteomics of CNS B-cell lymphoma patients showed that coagulation protein networks were highly connected with tumor-associated biological signaling pathways. In vivo two-photon imaging demonstrated that lymphoma growth was associated with BBB disruption, and in vitro experiments identified a role for fibrinogen in promoting lymphoma cell adhesion. Overall, these results identify perivascular lymphoma clustering at sites of fibrinogen deposition, and suggest that fibrinogen may be a target for pharmacologic intervention in metastatic B-cell lymphoma associated with BBB disruption. (Am J Pathol 2021, 191: 575-583; https://doi.org/10.1016/j.ajpath.2020.12.010)
\end{abstract}

Central nervous system (CNS) lymphoma is a form of nonHodgkin B-cell neoplasm that can occur as either a primary or a metastatic disease. ${ }^{1-3}$ Both primary and metastatic CNS lymphomas show accumulation of tumor cells around blood vessels, implicating the cerebrovasculature in their pathogenesis. ${ }^{2}$ Dissemination of lymphoma cells within the CNS is associated with poor prognosis. During CNS tumor development, the blood-brain barrier (BBB) can be damaged as a primary or a secondary event. ${ }^{4,5}$ Loss of integrity in the BBB closely correlates with how fast individual metastases grow, ${ }^{6}$ and meta-analyses indicate a significant association between BBB leakage and degree of malignancy. ${ }^{7,8}$ However, the relationship between BBB leakage and CNS lymphoma onset or progression has not been demonstrated.

BBB disruption allows plasma protein extravasation and deposition in the brain parenchyma. Indeed, a large-scale proteomic profiling of the cerebrospinal fluid (CSF) of patients with CNS lymphoma identified increased levels of coagulation factors, including fibrinogen, ${ }^{9}$ which correlated with tumor grade and poor clinical outcome. ${ }^{10}$ Interestingly, activation of the coagulation cascade seems to be crucial for tumor growth and metastasis-associated events. ${ }^{11}$ In addition, apart from its role in coagulation, fibrinogen has been shown to drive tissue inflammation during CNS injury and disease. ${ }^{12}$ However, whether fibrinogen is deposited in CNS tumors in lymphoma patients and its potential role in lymphoma accumulation in CNS tumors have not been investigated.

\footnotetext{
Supported by National Multiple Sclerosis Society Postdoctoral Fellowship (A.S.M.), NIH/National Institute of Neurological Disorders and Stroke R35NS097976 (K.A.), the Conrad N. Hilton Foundation 17348 (K.A.), the Simon Family Trust (K.A.), Leukemia and Lymphoma Society research grant (J.L.R.), NIH/National Cancer Institute research grants R01CA13983-01A1 and R01CA239462 (J.L.R.), Race to Erase Multiple Sclerosis Young Investigator Award (J.K.R.), and American Heart Association Scientist Development grant 16SDG30170014 (J.K.R).

Disclosures: None declared.
} 
This study makes use of human tumor samples and a mouse model of CNS lymphoma to investigate whether CSF protein extravasation through a permeable BBB can alter the tumor microenvironment to regulate the CNS tropism behavior and adhesion properties of CNS tumors. The results demonstrate that fibrinogen deposition occurs in the CNS parenchyma of an orthotopic mouse model of human B-cell lymphoma and in primary CNS lymphoma patients. Unbiased proteomic profiling of CSF from patients with metastatic B-cell CNS lymphoma revealed a molecular link between coagulation and signaling related to CNS lymphoma growth and progression. Lymphoma cells adhered to fibrinogen in vitro, and two-photon imaging of lymphoma in the brain showed that lymphoma tends to cluster around sites of BBB disruption. These data show, for the first time, the cellular and molecular interplay of fibrinogen and lymphoma growth signaling pathways, and can provide tumor-specific targets for pharmacologic intervention in lymphoma associated with BBB disruption.

\section{Materials and Methods}

\section{Cell Lines}

Raji, Ramos, and Ly3 cells were obtained from ATCC (Manassas, VA). Lymphoma cells were cultured in highglucose Dulbecco's modified Eagle's medium supplemented with $10 \%$ fetal calf serum, $1 \%$ penicillin-streptomycin, and $1 \%$ nonessential amino acids. To keep genetic drift to a minimum, cells were maintained in culture for a maximum duration of 2 to 3 months after thawing.

\section{Mice}

Athymic male mice (nu/nu; Simonsen Laboratories, Gilroy, CA) between the age of 4 and 6 weeks were used for tumor implantation experiments. Mice were housed under Institutional Animal Care and Use Committee guidelines in a temperature- and humidity-controlled facility with a 12-hour light-12-hour dark cycle and ad libitum feeding. All animal protocols were approved by the Committee on Animal Research at the University of California, San Francisco, and were in accordance with the NIH guidelines.

\section{Intracerebral Injection of Lymphoma Cells}

Raji cells were modified to stably express firefly luciferase by lentiviral transduction, as described. ${ }^{13}$ Cultured cells were washed three times with phosphate-buffered saline (PBS), counted, and maintained on ice in Dulbecco's modified Eagle's medium until injection. Athymic mice were anesthetized with a mixture of ketamine/xylazine and placed in a stereotactic frame. Raji cells $\left(5 \times 10^{5}\right.$ cells in 5 $\mu \mathrm{L}$ serum-free medium) were slowly injected at a rate of 1 $\mu \mathrm{L} /$ minute with a Hamilton syringe attached to a 26-gauge needle into the brain at the following coordinates: anteroposterior, $0.5 \mathrm{~mm}$; mediolateral, $-2.5 \mathrm{~mm}$; and dorsoventral, $-3 \mathrm{~mm}$ from the bregma.

\section{Functional Enrichment and Protein Network Analysis}

Network visualization was performed in Cytoscape version 3.7. $2^{14}$ with the plug-in for STRING Database. ${ }^{15}$ In brief, proteome data on differentially expressed proteins [false discovery rate $(\mathrm{FDR}),<0.1]$ that were increased in CSF from 31 patients with brain lymphoma compared with nonneoplastic control conditions ${ }^{9}$ were used as input (Supplemental Table S1) and queried in STRING Human Protein Database with default parameters. A total of 75 differentially expressed proteins were clustered on the basis of STRING functional enrichment analysis for Reactome pathways and ranked by FDR $P<0.05$ and $>10$ enriched proteins per Reactome pathway term.

\section{Immunohistochemistry}

Mice were transcardially perfused with PBS and 4\% paraformaldehyde under anesthesia, and brains were frozen in OCT compound (Tissue-Tek, Torrance, CA), then cut into $10-\mu \mathrm{m}$ cryosections. For immunohistochemistry, sections were permeabilized in $0.1 \%$ Triton X-100, blocked with $5 \%$ normal donkey serum, and incubated for 24 hours at $4{ }^{\circ} \mathrm{C}$ with primary antibodies against fibrinogen (1:1000), laminin (1:100; Sigma-Aldrich, St. Louis, MO), CD20 (1:500; BioLegend, San Diego, CA), CD11b (1:100; Abcam, Cambridge, MA), ionized calcium-binding adaptor protein1 (Iba-1; 1:1000; Wako, Richmond, VA), or CD31 (1:200; Abcam). Sections were rinsed in PBS with $0.1 \%$ Triton X100 and incubated with secondary antibodies conjugated with Alexa Fluor 488 or 594 (1:200; Jackson Immunochemicals, West Grove, PA) for 1 hour in the dark. After washing in PBS, sections were coverslipped with Prolong Gold antifading agent (Invitrogen, Carlsbad, CA). For diffuse large B-cell lymphoma and mucosa-associated lymphoma tissue array (US Biomax, Inc., Derwood, MD), deparaffinized sections were immunostained with fibrinogen antibody (1:1000). Images were acquired using an Axioplan II epifluorescence microscope (Zeiss, White Plains, NY) equipped with dry Plan-Neofluar objectives $(10 \times 0.3$, $20 \times 0.5$, or $40 \times 0.75$ numerical aperture).

\section{Cranial Window Surgery}

Mice were kept at $37^{\circ} \mathrm{C}$ using a heating pad during all surgical and imaging procedures. Surgery was performed under ketamine/xylazine anesthesia (100/10 mg/kg body weight). Following shaving of the head, disinfection of the skin, and local s.c. injection of $2 \%$ lidocaine, an incision was made to expose the skull. The skull was thoroughly dried by removing all bone-attached membrane and fat tissue. A circular moat of about 3 to $4 \mathrm{~mm}$ in diameter was drilled over the primary hindlimb/forelimb somatosensory cortex immediately above 
the implanted Raji cells. A custom-designed (eMachineShop, Mahwah, NJ) steel head bar that included an imaging chamber was positioned over the craniotomy and was firmly affixed to the skull with cyanoacrylate glue and Metabond dental cement. A drop of prewarmed $\left(37^{\circ} \mathrm{C}\right)$ artificial CSF (HEPES based; $125 \mathrm{mmol} / \mathrm{L} \mathrm{NaCl}, 10 \mathrm{mmol} / \mathrm{L}$ glucose, 10 $\mathrm{mmol} / \mathrm{L} \mathrm{HEPES}, 3.1 \mathrm{mmol} / \mathrm{L} \mathrm{CaCl}_{2}, 2.7 \mathrm{mmol} / \mathrm{L} \mathrm{KCl}$, and $1.3 \mathrm{mmol} / \mathrm{L} \mathrm{MgCl}_{2} ; \mathrm{pH}$ 7.4) was applied to the bone island. After 1 minute, the bone island was gently lifted off with a microscalpel blade (Nordland Blade number 6900; Salvin Dental, Charlotte, NC), followed by gentle flushing of the dura mater with prewarmed artificial CSF to clean and remove potential dural bleeding. A drop of artificial CSF was placed on top of the dura mater, and the craniotomy was closed and sealed using a round glass coverslip (4 $\mathrm{mm}$ in diameter, type 0; Warner Instruments, Holliston, MA), which was fixed to the skull and sealed with Flow-It ALC composite (Pentron, Orange, CA) cured under UV light.

\section{In Vivo Two-Photon Brain Microscopy}

An Ultima IV two-photon microscope (Prairie Technologies/ Bruker, Billerica, MA), equipped with a Mai Tai eHP DeepSee (Spectra-Physics/Newport, Santa Clara, CA) and an Insight X3 Ti:Sapphire femtosecond laser [Spectra-Physics/Newport; pulse width, $<120$ femtoseconds; tuning range, 690 to 1040 $\mathrm{nm}$ (Mai Tai) and 680 to $1300 \mathrm{~nm}$ (Insight X3); repetition rate, $80 \mathrm{MHz}$; Spectra-Physics/Newport], was used and tuned to an excitation wavelength of $950 \mathrm{~nm}$ (Mai Tai) and $1200 \mathrm{~nm}$ (Insight X3). Following retro-orbital injection of $100 \mu \mathrm{L}$ of 10 kDa Alexa 647-labeled dextran dissolved in artificial CSF, imaging was performed 50 to $100 \mu \mathrm{m}$ below the dura mater in the somatosensory cortex for vascular and tumor cell imaging. A $25 \times 1.05$ numerical aperture water-immersion lens (Olympus, Center Valley, PA) was used. Images were acquired in galvo scan mode at $512 \times 512$ pixels, $1.5 \mathrm{~Hz}$, and a $1.0-\mathrm{mm}$ z-step. The maximum laser power exiting the objective was $<40 \mathrm{~mW}$. An infrared-blocking filter and 560-nm dichroic were placed in the primary emission beam path before the nondescanned detectors. A 660-nm dichroic and a 692/24-nm $+607 / 45-\mathrm{nm}$ bandpass filter were used to separate Alexa 647-labeled dextran and red fluorescent protein emissions, respectively; a 520-nm dichroic and a 542/27-nm + 494/41-nm bandpass filter were used to separate yellow fluorescent protein and green fluorescent protein fluorescence emissions, respectively. A 45-minute time-lapse series, visualizing microglial morphology, Raji cell dynamics, and BBB leakage within a 60- to 70- $\mu \mathrm{m} \mathrm{Z-stack,} \mathrm{was} \mathrm{acquired} \mathrm{in} \mathrm{3-minute} \mathrm{intervals.} \mathrm{As}$ described, ${ }^{16,17}$ all imaging was performed at least $50 \mu \mathrm{m}$ below dura to avoid any potential effects of the cranial window surgery on cellular activity, survival, and BBB integrity.

\section{Processing and Analysis of in Vivo Imaging Data}

Three-dimensional reconstruction and volume rendering were performed with the three-dimensional Viewer plug-in within ImageJ software version 1.51 (NIH, Bethesda, MD; http://imagej.nih.gov/ij). Images were adjusted for brightness/contrast and background noise with ImageJ software using the Subtract Background and/or Remove Outliers plug-ins. For figures, two-dimensional representations of volumes were generated via maximum intensity projections along the $z$ axis using ImageJ software version 1 . 51. Time-lapse movies were generated using maximum intensity z-projections of stacks acquired sequentially over time. If drift occurred over the acquisition period, $\mathrm{z}$ shifts were corrected manually by taking substacks represented at all time points and lateral shifts were corrected with the StackReg plug-ins. Parenchymal movement tracking of individual Raji cells in the in vivo two-photon time-lapse Zstacks was accomplished by measuring the change in $x y$ coordinates of the pixels representing the edge of each identified moving Raji cell from time 0 (start of time-lapse imaging) to time 45 (end of time-lapse imaging). Total cell movement was defined as the sum of the change in $\mathrm{x}$ and $\mathrm{y}$ pixel coordinates. Tracking was performed in ImageJ software. Areas of BBB leakage were defined by the presence of intravenously injected fluorescent Alexa 647-labeled 70$\mathrm{kDa}$ dextran in the brain parenchyma, as previously described. ${ }^{16}$ For each time lapse interval, the presence or absence of parenchymal Alexa 647-labeled dextran was assessed by measuring the Alexa 647 fluorescence signal histogram in all extravascular/parenchymal space regions, as observed in the entire field of view. Only fields of view showing 0\% Alexa 647 fluorescence signal in all extravascular/parenchymal space regions and at all imaging time points were defined as areas without BBB leakage.

\section{Cell Adhesion Assay}

Blood was collected from the heart of anesthetized wild-type or $\mathrm{F} \mathrm{ga}^{-/-}$mice into one-tenth volume of sodium citrate (SigmaAldrich). Plasma was prepared by centrifugation at $2500 \times g$ for 10 minutes at room temperature. Lymphoma cells were incubated in PBS containing $0.1 \mu \mathrm{mol} / \mathrm{L}$ Calcein-AM (Invitrogen) for 20 minutes and 100,000 cells per well were plated on 96-well black $\mu$-clear-bottomed microtiter plates (Greiner Bio-One, Monroe, NC) precoated with plasma. Cells were incubated on plasma for 2 hours. The nonadherent cells were washed off with PBS, and Calcein-AM fluorescence was detected at $488 \mathrm{~nm} / 520 \mathrm{~nm}$ using a SpectraMax M5 microplate reader (Molecular Devices, San Jose, CA).

\section{Statistical Analysis}

Data are presented as means \pm SEM. Statistical calculations were performed with GraphPad Prism version 6.03 (GraphPad Software, San Jose, CA). Statistical significance was determined with a nonparametric two-sided $U$-test or two-way analysis of variance, followed by the Tukey posttest (multiple comparisons). All animals survived to the end of the study, and all data points were included in analysis. 
Regulation of complement cascade $\left(\right.$ FDR $\left.=5.45 \times 10^{-26}\right)$

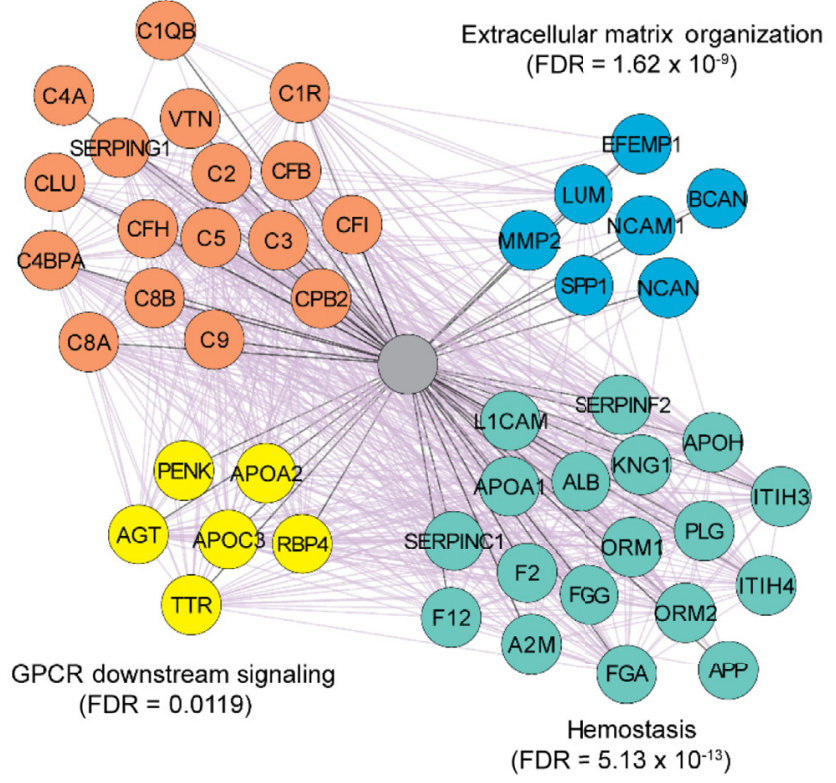

B

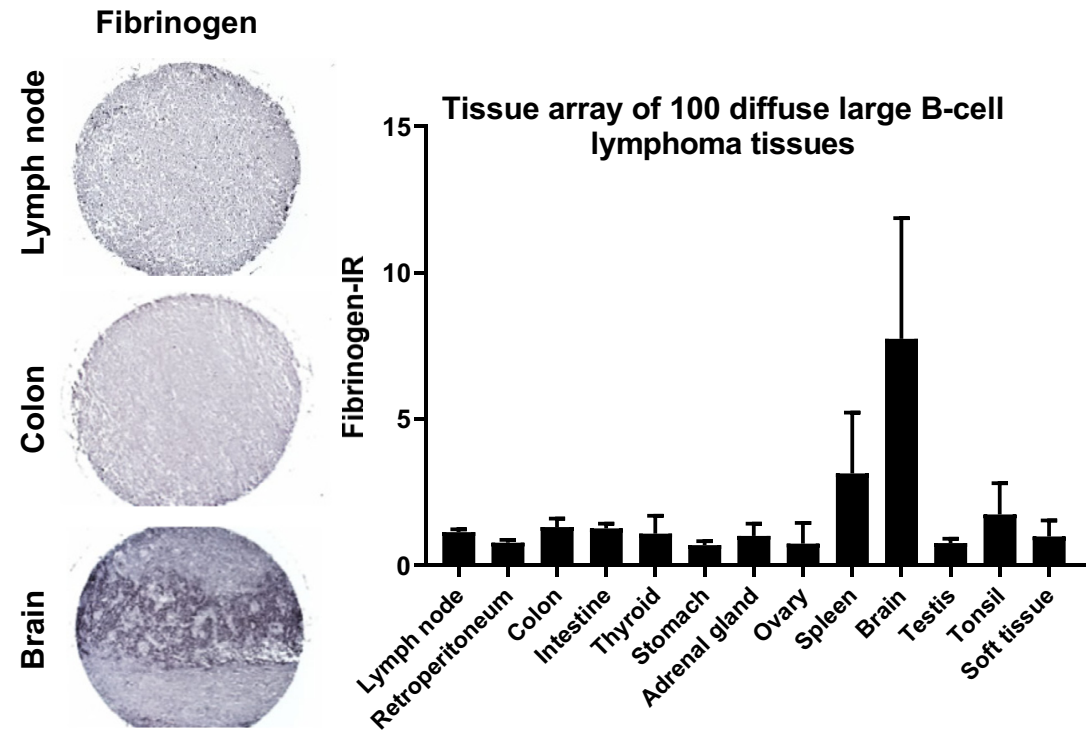

Figure 1 Coagulation factors are required for lymphoma formation in the brain. A: Network of co-expressed proteins in cerebrospinal fluid from cancer patients. Nodes (circles) of the network represent proteins, and the edges (purple lines) between two nodes indicate published evidence for co-expression. Nodes are colored on the basis of functional categories significantly enriched in Reactome pathway terms [false discovery rate (FDR), <0.05]. B: Tissue array of 100 diffuse large B-cell lymphomas in specified tissues. Immunohistochemistry of fibrinogen deposits in specified tissue array comprising 100 malignant diffuse large B-cell lymphomas. Representative fibrinogen-staining tissues from lymph node and brain are shown. Data are given as means \pm SEM (B). GPCR, G protein-coupled receptors; IR, immunoreactivity.
All histopathologic analysis and quantification were performed blinded to experimental groups.

\section{Results}

\section{Biological Categorization of Significantly Altered Proteins in CNS Lymphoma Patients}

The proteome of the CSF of CNS lymphoma patients has been shown to differ significantly from that of control CSF. ${ }^{9}$
Although analysis of CSF proteins provides potential diagnostic and prognostic biomarker information, the above study did not reveal how the proteins found in the CSF may interact to promote CNS lymphoma. To fill this gap, CSF proteome data were subjected to a STRING functional enrichment analysis to rank Reactome pathway terms (Figure 1A and Supplemental Table S2). This analysis reveals functional links between proteins that may contribute jointly to a specific biological function. Because several annotations are branched together, the analysis was 

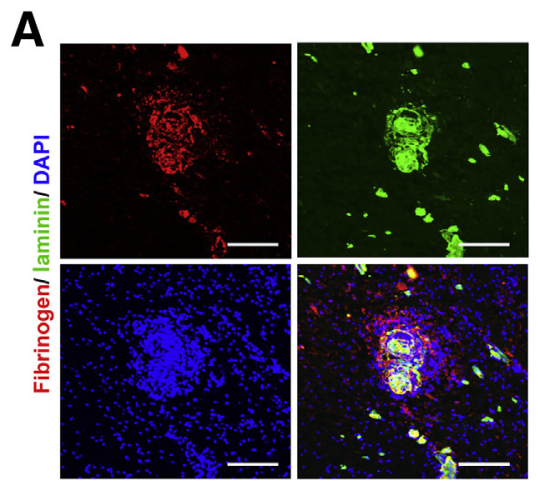

B

\section{CNS lymphoma patients}

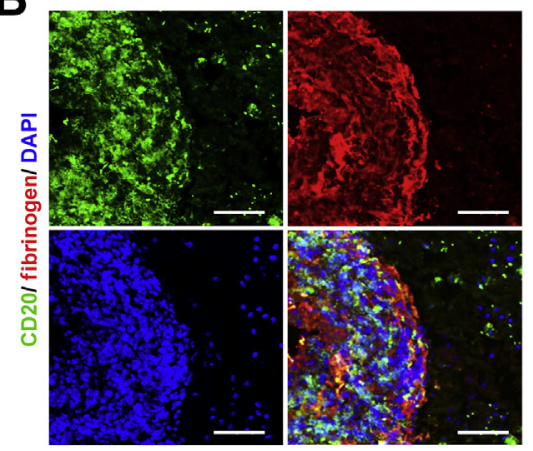

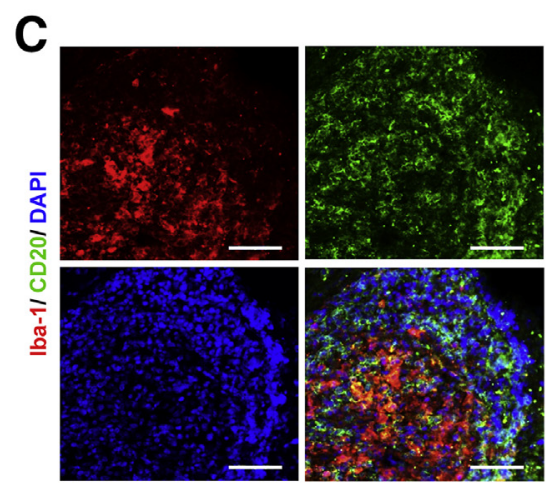

Figure 2 Fibrinogen is associated with central nervous system (CNS) lymphoma. Microscopy of tissue sections from postmortem brains of human patients with CNS lymphoma, stained with antibodies to fibrinogen, laminin (basal membrane), CD20 (B cell), and ionized calcium-binding adaptor protein-1 (Iba-1; microglia), showing fibrinogen surrounding a CD20+ B-cell lymphoma around leaky blood vessels. Scale bars: $100 \mu \mathrm{m}(\mathbf{A}) ; 80 \mu \mathrm{m}(\mathbf{B}$ and C).

visualized as an enrichment network, which algorithmically clustered Reactome pathway terms with highly similar content, using the enrichment map plug-in in the Cytoscape environment. This revealed the highly connected pathways regulation of complement cascade $\left(\mathrm{FDR}=5.45 \times 10^{-26}\right)$, extracellular matrix organization $\left(\mathrm{FDR}=1.62 \times 10^{-9}\right), \mathrm{G}$ protein-coupled receptors downstream signaling $(\mathrm{FDR}=0.0119)$, and hemostasis $\left(\mathrm{FDR}=5.13 \times 10^{-13}\right)$. These data identified 37 coagulation proteins (hemostasis and regulation of complement cascade) that are significantly deregulated in CSF of CNS lymphoma patients and connected with tumor-associated biological signaling, increased extracellular matrix deposition, and $\mathrm{G}$ protein-coupled receptors signaling, and support a role for BBB disruption as a primary driver of lymphoma growth and progression.

\section{Fibrinogen Deposits Are Abundant in Brain Specimens from Patients with B-Cell Lymphoma}

To determine whether fibrinogen forms deposits in B-cell lymphoma, immunohistochemical staining was performed on tissue arrays containing the malignant cores of diffuse large B-cell lymphoma $(n=72)$ and of mucosa-associated lymphoma $(n=28)$ in specified tissue specimens. Most CNS lymphoma specimens exhibited moderate to high levels of fibrinogen deposits, whereas lymph node and colon tissues had no observable immunoreactivity (Figure 1B). Given the reported correlation between BBB leakage and poor prognosis for CNS lymphoma patients, ${ }^{7,8}$ presence of accumulated fibrinogen was examined in the brain of primary CNS lymphoma patients. To further characterize the localization of the fibrinogen deposits, immunostaining with an anti-pan laminin antibody was performed to detect the inner (endothelial) and outer (parenchymal) basement membrane. Fibrinogen was detected in the CNS parenchyma, including as extravascular deposits, as shown by double immunostaining with laminin (Figure 2A). Perivascular fibrinogen deposits were found close to $\mathrm{CD} 20^{+}$lymphoma cells, suggesting the formation of a perivascular cuffing pattern, with lymphoma cells clustering around leaky blood vessels (Figure 2B). Perivascular B-cell lymphoma cells were also in close proximity to Iba- $1^{+}$macrophage- or microglialike cells (Figure 2C). Thus, perivascular fibrin deposition may be a key spatial determinant of perivascular B-cell lymphoma clustering and microglia or macrophage accumulation in primary CNS lymphoma.

\section{Perivascular Lymphomas Cluster Near Fibrinogen Deposits in Mouse Brains Injected with Cells from Patients with Primary CNS Lymphoma}

To investigate the spatial correlation of BBB disruption with lymphoma growth, an orthotopic xenograft model of human CNS B-cell lymphoma in mice was used. Lymphoma cells from primary CNS lymphoma patients were stereotaxically injected into the cortex of Rag $2^{-/} \gamma \mathrm{C}^{-/}$mice, which lack B, $\mathrm{T}$, and natural killer cells (Figure 3) ${ }^{18,19}$ Extravascular fibrinogen in the brain was assessed by the presence of fibrinogen immunoreactive areas outside $\mathrm{CD} 31^{+}$blood vessels. At the peak of the disease, day 14 after tumor transplantation, immunofluorescence staining revealed massive extravascular fibrinogen deposits around CD31 ${ }^{+}$ blood vessels in the core and periphery of the lymphoma (Figure 3, A and B). As expected, ${ }^{20}$ CNS tumor blood vessels were structurally abnormal at the tumor-host interface and at central regions and differed from vessels in nontumor areas (Figure 3, A-C). Areas with no tumor had no observable extravascular fibrinogen immunoreactivity (Figure 3C). Double staining for CD20 and fibrinogen showed lymphoma cells clustered around blood vessel leaks stained with fibrinogen (Figure 3D), suggesting that the injected lymphoma cells may adhere to fibrinogen deposits. Previous studies reported a direct correlation between tumor size and increased capillary permeability at the late stage of tumor progression, and only minimal contribution of the implant procedure to BBB permeability. ${ }^{21,22}$ To determine 

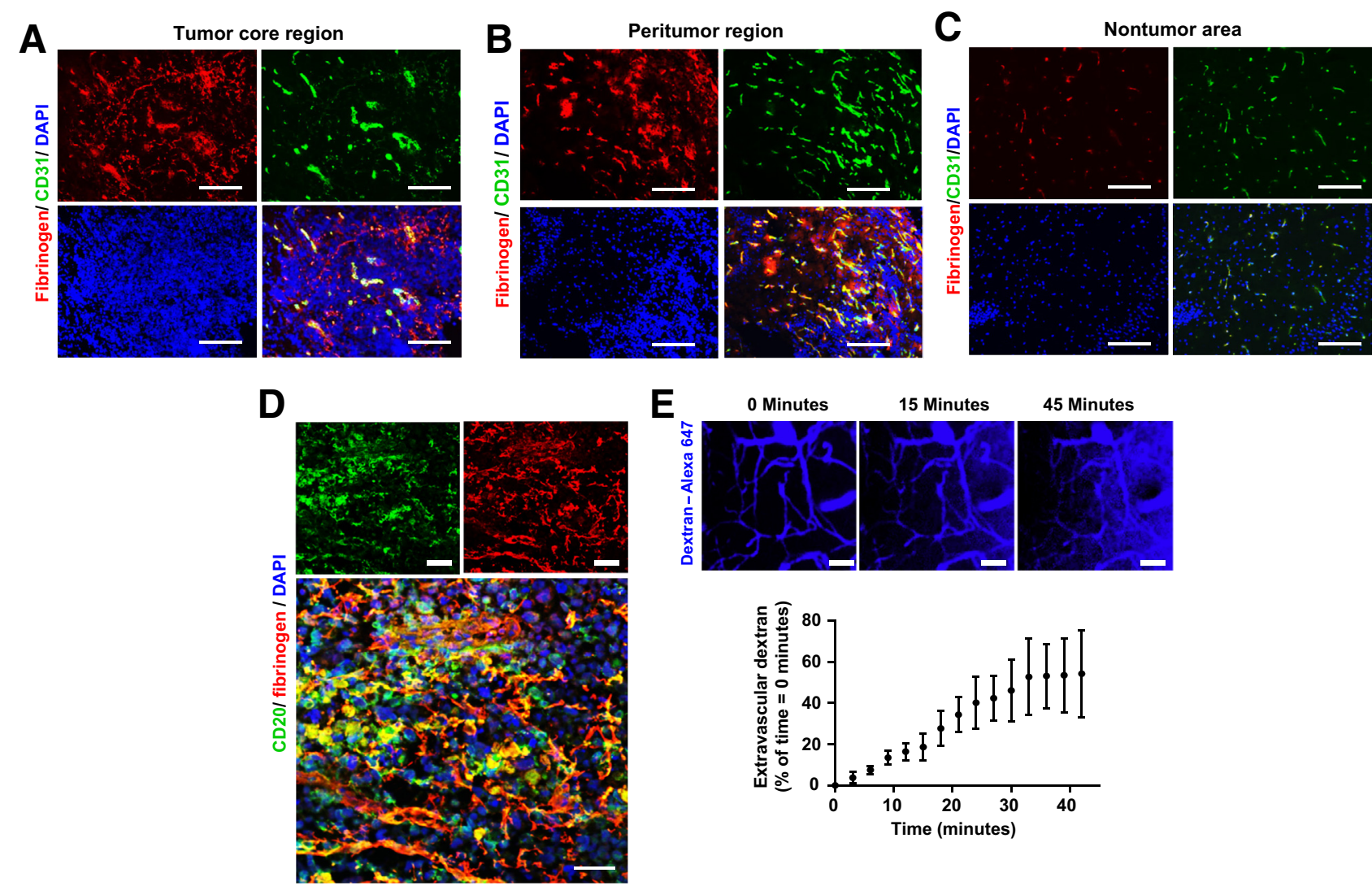

Figure 3 Central nervous system (CNS) lymphoma is associated with leaky blood-brain barrier (BBB). A-D: Microscopy of tissue sections of mouse brain implanted with B-cell lymphoma derived from CNS lymphoma patients, stained with antibodies to fibrinogen, CD31 (endothelial cells), and CD20 (B cell), showing patient-derived xenografted lymphoma cells are accumulated around leaky BBB. E: Top panels: In vivo two-photon (2P) brain imaging of BBB leaks (detection of Alexa 647-labeled dextran) in the cortex of a mouse brain implanted with B-cell lymphoma Raji cells. Bottom panel: Quantification of extravascular dextran in cortex. Data are given as means \pm SEM (E, bottom panel). $n=3$ mice (E, bottom panel). Scale bars: $150 \mu \mathrm{m}(\mathbf{A}-\mathbf{C}) ; 50 \mu \mathrm{m}$ (D and $\mathbf{E})$.

whether malignant lymphoma cells cause BBB leaks, realtime in vivo tracking of active BBB leakage was performed in live mice injected intracerebrally with human B-cell lymphoma Raji cells (Figure 3E). Imaging started immediately after a bolus i.v. injection of a fluorescently labeled dextran solution (blue). Parenchymal tumor clusters correlated with sites of active BBB disruption (Figure 3E). These results identify active BBB leaks at sites of B-cell lymphoma in the CNS.

\section{Fibrinogen Induces Lymphoma Cell Adhesion}

Over time, intravascular fluorescent dextran gradually leaked into the perivascular tissue that was occupied by lymphoma cells (Supplemental Figure S1). Time-lapse imaging and cell tracking showed that perivascular tumor cells at the site of BBB leakage exhibited reduced cell motility compared with cells distal to the BBB leakage areas (Figure 4A). Furthermore, lymphoma cells at leakage sites were mostly lodged (94\%), whereas cells at adjacent perivascular areas without leakage were either lodged (60\%) or moving (40\%) (Figure 4B). In cell adhesion assays, fibrinogen coating induced significantly more adhesion of lymphoma cells than the blood protein albumin or an uncoated surface (Figure 4C). Coating with wild-type plasma also induced lymphoma adhesion. In contrast, lymphoma adhesion was markedly lower with plasma from $\mathrm{Fga}^{-/-}$mice, which contain virtually every plasma protein with the exception of fibrinogen (Figure 4D). Overall, these results suggest that fibrinogen is a major plasma protein facilitating adhesion of lymphoma cells at sites of BBB disruption.

\section{Discussion}

This study provides the first demonstration that fibrinogen deposits associated with lymphoma accumulation are a critical component of perivascular cuffing in CNS lymphoma patients. Reactome pathway analysis revealed that functional links between coagulation and hemostasis proteins contribute jointly to a specific functional CNS signaling pathway associated with lymphoma progression in CNS lymphoma patients. Using in vivo two-photon imaging in a mouse model of CNS lymphoma, lymphoma clusters were identified early, which increased with BBB disruption. These results further show that extravasated fibrinogen may 
A

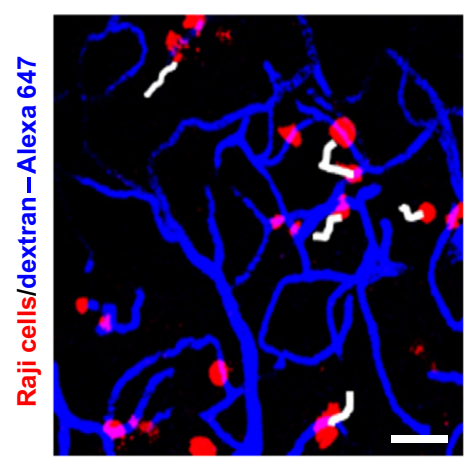

B

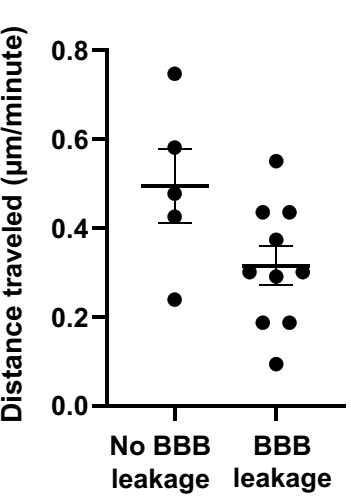

Lodged cells

Moving cells

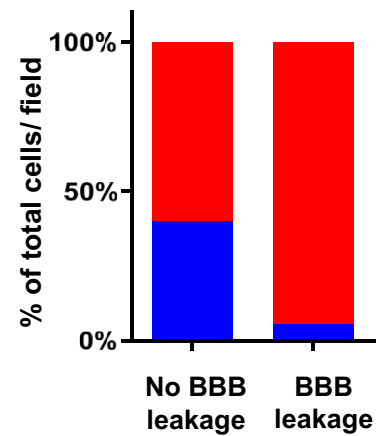

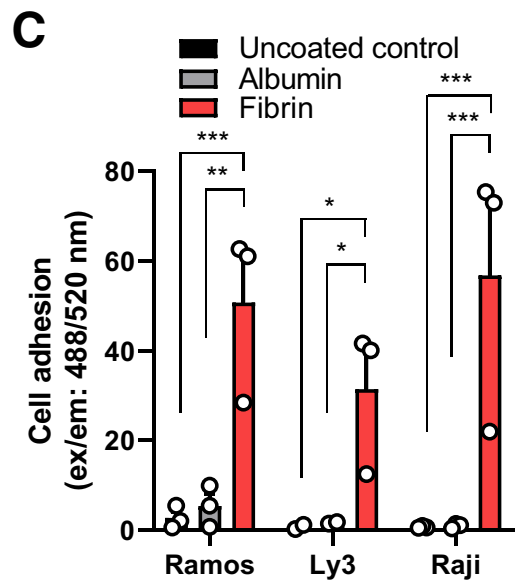

D

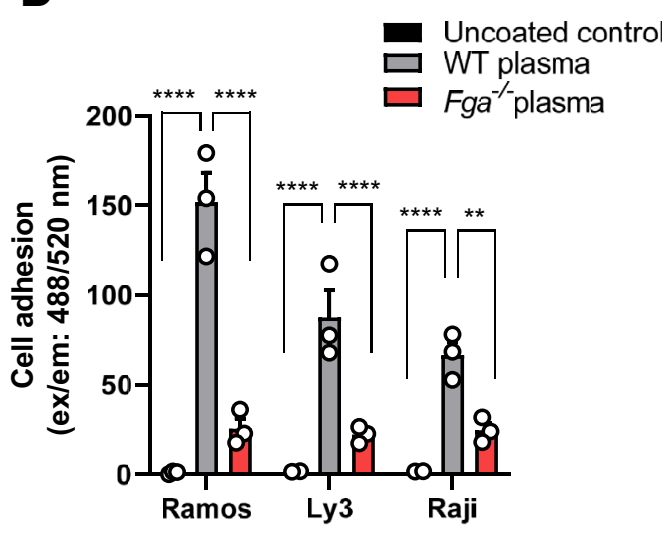

Figure 4 In vivo two-photon (2P) imaging of parenchymal movement of brain-implanted Raji cells in regions with and without blood-brain barrier (BBB) leakage. A: In vivo 2P time-lapse images, showing tracking of intracortical movement of Raji cells in Raji cell-implanted mice over 45 minutes. White tracks indicate cells showing movement over the 45-minute imaging interval. B: Quantification of traveled distance measured over 45 minutes, shown in A. Data are shown for individual cells (five cells per mouse) and as averages of five cells per mouse. C: Lymphoma cell adhesion assay. Quantification of adhered lymphoma cells labeled with Calcein-AM on different coating conditions: uncoated, fibrinogen, and albumin. D: Quantification of adhered lymphoma cells to coated plasma isolated from wild-type and $\mathrm{Fga}^{-/}$mice. Data are given as means $\pm \mathrm{SEM}(\mathbf{C}$ and $\mathbf{D}) . n=3$ mice with BBB leakage and without BBB leakage $(\mathbf{B}) ; n=3$ independent experiments (C and $\mathbf{D})$. ${ }^{*} P<0.05,{ }^{*} P P<0.01,{ }^{* * *} P<0.001$, and ${ }^{* * * *} P<0.0001$ (two-way analysis of variance with the Tukey multiplecomparisons test). Scale bar $=25 \mu \mathrm{m}(\mathbf{A})$. Ex/em, excitation/emission.

act to retain CNS lymphoma cells near sites of BBB leakage by increasing cancer cell adhesion.

The formation of CNS lymphoma around sites of fibrin deposition suggests that activation of the coagulation cascade is crucial for tumor growth and metastasisassociated events. However, the role of fibrinogen is not restricted to blood clotting, as components of the coagulation cascade within solid tissues ${ }^{23,24}$ convert soluble fibrinogen into insoluble fibrin, which provides a provisional adhesive matrix for tumor cells. ${ }^{25-27}$ Furthermore, previous studies have identified fibrinogen as a molecular link between BBB disruption and neuroinflammation, as fibrinogen interacts with the CD11b/CD18 integrins expressed on microglia and infiltrating macrophages, activating proinflammatory signaling. ${ }^{16,28-30}$ Thus, the fibrinogen deposits around BBB leaks in CNS lymphoma could mediate the local inflammatory response and affect disease progression.

Notably, the immunohistochemical methods used in this study do not discriminate between fibrinogen and fibrin. However, on activation of the coagulation cascade, conversion of fibrinogen to fibrin is associated with exposure of cryptic epitopes that transform fibrinogen from a blood factor to a potent activator of innate immunity, by allowing interaction with the $\mathrm{CD} 11 \mathrm{~b}$ integrin receptor. ${ }^{30,31}$ This may facilitate the clustering and subsequent growth progression of lymphoma cells. Future studies will explore the contribution of the coagulation cascade in lymphoma.

This study used mouse CNS lymphoma as an experimental setting to explore pathogenic events associated with fibrinogen leakage in the CNS. However, it is important to note that the mouse model does not recapitulate the 
complexity of perivascular cuffing in human lymphoma. In the mouse model, the spatial distribution of Raji cells around sites of BBB disruption may indicate that lymphoma cell localization drives BBB disruption with leakage of fibrinogen; however, further studies are needed to elucidate whether this pattern holds true in human CNS lymphoma.

There is a well-established link between tumor malignancy and altered hemostasis. Tumors rely heavily on blood supply for growth, and fibrin deposited within tumors is thought to promote angiogenesis by acting as a scaffold for vessel formation. ${ }^{32}$ The implication of fibrinogen in primary CNS lymphoma growth and adhesion is an important link in understanding the relationship between BBB disruption and lymphoma pathogenesis. Histologic evidence of fibrinogen accumulation in close association with lymphoma cell clustering in both a rodent model and human specimens suggests that fibrinogen could be a key factor in the bloodstream, promoting tumor progression. Intriguingly, analysis of plasma samples from $\mathrm{Fga}^{-/-}$mice highlighted that fibrinogen is a major player among blood proteins in its ability to promote lymphoma adhesion. Taken together, the extent and nature of interaction of lymphoma with fibrinogen reported herein, and the early stage at which these interactions emerge, support the role of fibrinogen in the initial stages of disease pathogenesis. Whether it also supports a role for fibrinogen in the later stages of tumor growth and a causal link with metastasis remains to be determined.

Given the potential role of blood coagulation factors in tumor progression, anticoagulants may represent a valid therapeutic approach. However, anticoagulants may interfere with coagulation in a non-specific manner, which could be detrimental to tumor patients. Furthermore, anticoagulants may affect the initial steps of tumor dissemination, such as tumor cell detachment from the extracellular matrix, invasion of surrounding tissues, and access to the systemic circulation. $^{33}$ The current studies suggest that fibrinogen deposition is an important step of perivascular cuffing during the initial stages of CNS lymphoma formation, suggesting that targeting fibrin might influence lymphoma cell survival in a new microenvironment through interference with perivascular cuffing. The therapeutic potential of genetically or pharmacologically targeting the fibrinogen$\mathrm{CD} 11 \mathrm{~b}$ interaction without compromising the coagulation properties of fibrinogen has been demonstrated in different animal models of CNS diseases. ${ }^{17,29,30,34}$ Similar approaches may be a promising strategy to target the early stages of CNS lymphomas.

\section{Acknowledgments}

We thank Rosa Meza-Acevedo and Belinda Cabriga for technical assistance; and Francoise Chanut and Kathryn Claiborn for editorial assistance.

\section{Author Contributions}

J.P.C, M.M., and J.K.R. performed and designed experiments and analyzed data; H.G. performed experiments; A.S.M. analyzed proteomic data; K.A. designed experiments and analyzed data; J.L.R. and J.K.R. conceived the project, designed the study, designed experiments, and analyzed data; J.P.C. and J.K.R. wrote the manuscript, with input from all authors; all authors contributed to critical review of the manuscript.

\section{Supplemental Data}

Supplemental material for this article can be found at http://doi.org/10.1016/j.ajpath.2020.12.010.

\section{References}

1. Hochberg FH, Miller DC: Primary central nervous system lymphoma. J Neurosurg 1988, 68:835-853

2. Rubenstein JL, Fridlyand J, Shen A, Aldape K, Ginzinger D, Batchelor T, Treseler P, Berger M, McDermott M, Prados M, Karch J, Okada C, Hyun W, Parikh S, Haqq C, Shuman M: Gene expression and angiotropism in primary CNS lymphoma. Blood 2006, 107:3716-3723

3. Wang CC, Carnevale J, Rubenstein JL: Progress in central nervous system lymphomas. Br J Haematol 2014, 166:311-325

4. Dubois LG, Campanati L, Righy C, D’Andrea-Meira I, Spohr TC Porto-Carreiro I, Pereira CM, Balca-Silva J, Kahn SA, DosSantos MF, Oliveira Mde A, Ximenes-da-Silva A, Lopes MC, Faveret E, Gasparetto EL, Moura-Neto V: Gliomas and the vascular fragility of the blood brain barrier. Front Cell Neurosci 2014, 8:418

5. Lee J, Lund-Smith C, Borboa A, Gonzalez AM, Baird A, Eliceiri BP: Glioma-induced remodeling of the neurovascular unit. Brain Res 2009, 1288:125-134

6. Osswald M, Blaes J, Liao Y, Solecki G, Gommel M, Berghoff AS, Salphati L, Wallin JJ, Phillips HS, Wick W, Winkler F: Impact of blood-brain barrier integrity on tumor growth and therapy response in brain metastases. Clin Cancer Res 2016, 22:6078-6087

7. Wang PF, Meng Z, Song HW, Yao K, Duan ZJ, Li SW, Yan CX: Higher plasma fibrinogen levels are associated with malignant phenotype and worse survival in patients with glioblastomas. J Cancer 2018, 9:2024-2029

8. Perisanidis C, Psyrri A, Cohen EE, Engelmann J, Heinze G, Perisanidis B, Stift A, Filipits M, Kornek G, Nkenke E: Prognostic role of pretreatment plasma fibrinogen in patients with solid tumors: a systematic review and meta-analysis. Cancer Treat Rev 2015, 41: 960-970

9. Roy S, Josephson SA, Fridlyand J, Karch J, Kadoch C, Karrim J, Damon L, Treseler P, Kunwar S, Shuman MA, Jones T, Becker CH, Schulman H, Rubenstein JL: Protein biomarker identification in the CSF of patients with CNS lymphoma. J Clin Oncol 2008, 26: 96-105

10. Troppan KT, Melchardt T, Wenzl K, Schlick K, Deutsch A, Bullock MD, Reitz D, Beham-Schmid C, Weiss L, Neureiter D, Trankenschuh W, Greil R, Neumeister P, Egle A, Pichler M: The clinical significance of fibrinogen plasma levels in patients with diffuse large B cell lymphoma. J Clin Pathol 2016, 69:326-330

11. Francis JL, Biggerstaff J, Amirkhosravi A: Hemostasis and malignancy. Semin Thromb Hemost 1998, 24:93-109 
12. Petersen MA, Ryu JK, Akassoglou K: Fibrinogen in neurological diseases: mechanisms, imaging and therapeutics. Nat Rev Neurosci 2018, 19:283-301

13. Kadoch C, Dinca EB, Voicu R, Chen L, Nguyen D, Parikh S, Karrim J, Shuman MA, Lowell CA, Treseler PA, James CD, Rubenstein JL: Pathologic correlates of primary central nervous system lymphoma defined in an orthotopic xenograft model. Clin Cancer Res 2009, 15:1989-1997

14. Shannon P, Markiel A, Ozier O, Baliga NS, Wang JT, Ramage D, Amin N, Schwikowski B, Ideker T: Cytoscape: a software environment for integrated models of biomolecular interaction networks. Genome Res 2003, 13:2498-2504

15. Szklarczyk D, Morris JH, Cook H, Kuhn M, Wyder S, Simonovic M, Santos A, Doncheva NT, Roth A, Bork P, Jensen LJ, von Mering C: The STRING database in 2017: quality-controlled protein-protein association networks, made broadly accessible. Nucleic Acids Res 2017, 45:D362-D368

16. Davalos D, Ryu JK, Merlini M, Baeten KM, Le Moan N, Petersen MA, Deerinck TJ, Smirnoff DS, Bedard C, Hakozaki H, Gonias Murray S, Ling JB, Lassmann H, Degen JL, Ellisman MH, Akassoglou K: Fibrinogen-induced perivascular microglial clustering is required for the development of axonal damage in neuroinflammation. Nat Commun 2012, 3:1227

17. Merlini M, Rafalski VA, Rios Coronado PE, Gill TM, Ellisman M, Muthukumar G, Subramanian KS, Ryu JK, Syme CA, Davalos D, Seeley WW, Mucke L, Nelson RB, Akassoglou K: Fibrinogen induces microglia-mediated spine elimination and cognitive impairment in an Alzheimer's disease model. Neuron 2019, 101:1099-1108.e6

18. Rubenstein JL, Wong VS, Kadoch C, Gao HX, Barajas R, Chen L, Josephson SA, Scott B, Douglas V, Maiti M, Kaplan LD, Treseler PA, Cha S, Hwang JH, Cinque P, Cyster JG, Lowell C: CXCL13 plus interleukin 10 is highly specific for the diagnosis of CNS lymphoma. Blood 2013, 121:4740-4748

19. Geng H, Gao H, Kadoch C, Lu M, Chen L, Anjum R, Drew L, Degorce S, Dillman K, Mayo M, Anderson S, Collins C, Lowell CA, Rubenstein JL: Targeting NF-KB activation in novel intracranial models of CNS lymphoma. Blood 2016, 128:777

20. Nagy JA, Chang SH, Dvorak AM, Dvorak HF: Why are tumour blood vessels abnormal and why is it important to know? Br J Cancer 2009, 100:865-869

21. Hiesiger EM, Voorhies RM, Basler GA, Lipschutz LE, Posner JB, Shapiro WR: Opening the blood-brain and blood-tumor barriers in experimental rat brain tumors: the effect of intracarotid hyperosmolar mannitol on capillary permeability and blood flow. Ann Neurol 1986, 19:50-59

22. Wiranowska M, Gonzalvo AA, Saporta S, Gonzalez OR, Prockop LD: Evaluation of blood-brain barrier permeability and the effect of interferon in mouse glioma model. J Neurooncol 1992, 14: $225-236$

23. Furie B, Furie BC: The molecular basis of blood coagulation. Cell 1988, 53:505-518

24. Davalos D, Akassoglou K: Fibrinogen as a key regulator of inflammation in disease. Semin Immunopathol 2012, 34:43-62

25. Dvorak HF, Nagy JA, Berse B, Brown LF, Yeo KT, Yeo TK, Dvorak AM, van de Water L, Sioussat TM, Senger DR: Vascular permeability factor, fibrin, and the pathogenesis of tumor stroma formation. Ann N Y Acad Sci 1992, 667:101-111

26. Harris NL, Dvorak AM, Smith J, Dvorak HF: Fibrin deposits in Hodgkin's disease. Am J Pathol 1982, 108:119-129

27. Bardos H, Molnar P, Csecsei G, Adany R: Fibrin deposition in primary and metastatic human brain tumours. Blood Coagul Fibrinolysis 1996, 7:536-548

28. Ryu JK, Petersen MA, Murray SG, Baeten KM, Meyer-Franke A, Chan JP, Vagena E, Bedard C, Machado MR, Rios Coronado PE, Prod'homme T, Charo IF, Lassmann H, Degen JL, Zamvil SS, Akassoglou K: Blood coagulation protein fibrinogen promotes autoimmunity and demyelination via chemokine release and antigen presentation. Nat Commun 2015, 6:8164

29. Adams RA, Bauer J, Flick MJ, Sikorski SL, Nuriel T, Lassmann H, Degen JL, Akassoglou K: The fibrin-derived gamma377-395 peptide inhibits microglia activation and suppresses relapsing paralysis in central nervous system autoimmune disease. J Exp Med 2007, 204:571-582

30. Ryu JK, Rafalski VA, Meyer-Franke A, Adams RA, Poda SB, Rios Coronado PE, Pedersen LO, Menon V, Baeten KM, Sikorski SL, Bedard C, Hanspers K, Bardehle S, Mendiola AS, Davalos D, Machado MR, Chan JP, Plastira I, Petersen MA, Pfaff SJ, Ang KK, Hallenbeck KK, Syme C, Hakozaki H, Ellisman MH, Swanson RA, Zamvil SS, Arkin MR, Zorn SH, Pico AR, Mucke L, Freedman SB, Stavenhagen JB, Nelson RB, Akassoglou K: Fibrin-targeting immunotherapy protects against neuroinflammation and neurodegeneration. Nat Immunol 2018, 19:1212-1223

31. Davalos D, Baeten KM, Whitney MA, Mullins ES, Friedman B, Olson ES, Ryu JK, Smirnoff DS, Petersen MA, Bedard C, Degen JL, Tsien RY, Akassoglou K: Early detection of thrombin activity in neuroinflammatory disease. Ann Neurol 2014, 75: 303-308

32. Daly ME, Makris A, Reed M, Lewis CE: Hemostatic regulators of tumor angiogenesis: a source of antiangiogenic agents for cancer treatment? J Natl Cancer Inst 2003, 95:1660-1673

33. Hejna M, Raderer M, Zielinski CC: Inhibition of metastases by anticoagulants. J Natl Cancer Inst 1999, 91:22-36

34. Akassoglou K: The immunology of blood: connecting the dots at the neurovascular interface. Nat Immunol 2020, 21: $710-712$ 